\title{
Longitudinal study of Salmonella spp., diarrheagenic Escherichia coli, Rotavirus, and Coronavirus isolated from healthy and diarrheic calves in a Brazilian dairy herd
}

\author{
Fernanda Morcatti Coura • Moisés Dias Freitas • Juliane Ribeiro • Raquel Arruda de Leme • \\ Cecília de Souza • Amauri Alcindo Alfieri • Elias Jorge Facury Filho • \\ Antônio Último de Carvalho • Marcos Xavier Silva • Andrey Pereira Lage • \\ Marcos Bryan Heinemann
}

Received: 15 April 2014 / Accepted: 16 September 2014 / Published online: 14 October 2014

(C) Springer Science+Business Media Dordrecht 2014

\begin{abstract}
This prospective longitudinal study investigated the epidemiology of enteric disease associated with infections in calves aging up to 70 days. A total of 850 fecal samples were collected from 67 calves. Seventeen isolates of Salmonella spp. were recovered from feces of 11 calves (16.4\%), and statistical analysis revealed no association between the presence of Salmonella spp. and clinical signs of diarrhea or age. Virulence factors of Escherichia coli were identified in 103 strains: eae (7), K99/STa (7), Stx1 (7), Stx1/eae (36), Stx1/Stx2/eae (2), Stx2 (43), and Stx2/eae (1). There was statistical association between diarrheic animals carrying E. coli Stx 1/eae in their feces at 2 and 4 weeks of age $(P=$ $0.003)$ and $E$. coli Stx $2^{+}$at 5 weeks of age $(P=0.03)$. Rotavirus was detected in $49(5.76 \%)$ fecal samples collected from 33 calves $(49.2 \%)$. The presence of rotavirus was correlated with
\end{abstract}

\section{F. M. Coura $\cdot$ M. X. Silva • A. P. Lage}

Departamento de Medicina Veterinária Preventiva, Escola de

Veterinária, Universidade Federal de Minas Gerais, Av. Antônio

Carlos, 6627, Belo Horizonte, Minas Gerais 31270-010, Brazil

M. D. Freitas · E. J. Facury Filho • A. Ú. de Carvalho Departamento de Clínica e Cirurgia Veterinária, Escola de Veterinária, Universidade Federal de Minas Gerais, Av. Antônio Carlos, 6627, Belo Horizonte, Minas Gerais 31270-010, Brazil

J. Ribeiro $\cdot$ R. A. de Leme $\cdot$ C. de Souza $\cdot$ A. A. Alfieri Departamento de Medicina Veterinária Preventiva, Universidade Estadual de Londrina, C.P. 6001, Londrina, Paraná 86051-990, Brazil

M. B. Heinemann $(\triangle)$

Departamento de Medicina Veterinária Preventiva e Saúde Animal, Faculdade de Medicina Veterinária e Zootecnia, Universidade de São Paulo, Av. Prof. Dr. Orlando Marques de Paiva, 87, São Paulo 05508-270, Brazil

e-mail: marcosbryan@usp.br diarrheic feces $(P<0.0001)$ rather than feces with normal consistency. There was a significant relationship between age group and diarrhea $(P=0.001)$. Bovine coronavirus $(\mathrm{BCoV})$ was detected in 93 fecal samples collected from 46 calves $(68.6 \%)$. There was an association $(P<0.0001)$ between diarrheic animals positive for $\mathrm{BCoV}$ and age groups. The results demonstrate the importance of the pathogens studied in the etiology of diarrhea in calves.

Keywords Calf diarrhea - Coronavirus - Escherichia coli . Rotavirus · Salmonella spp.

\section{Introduction}

Diarrhea is an important disease of young calves and has a complex etiopathogenesis, with the association of several infectious agents, either alone or in combination, host factors, and non-infectious factors, such as environment, management practices, and nutrition (Blanchard 2012). Salmonella spp., pathogenic Escherichia coli, coronavirus, and rotavirus are the most frequent pathogens associated with diarrhea in calves (Foster and Smith 2009). The cattle industry has made great technological improvements, but calf diarrhea is still the most important cause of economic loss to cattle producers worldwide (Cho and Yoon 2014).

Salmonella spp. induce different disease manifestations in cattle that reflect the virulence of different serotypes, challenge dose, and host immunity. Salmonellosis in calves occurs mostly at 2-6 weeks of age (Barrow et al. 2010). The genus Salmonella contains two species (Salmonella enterica and Salmonella bongori) and over 2500 serotypes (Brenner et al. 2000). Many serotypes can infect those animals, but serotypes 
Dublin and Typhimurium are the most commonly isolated ones (Cummings et al. 2009a). The pathophysiology of enteric Salmonella infection is complex, involving inflammation and necrosis (Barrow et al. 2010).

$E$. coli is a major component of normal intestinal microbiota of animals, and differentiation of pathogenic strains from normal microbiota is based on the production of virulence factors and on the identification of mechanisms by which they cause disease, which allow their classification into pathotypes. Enterotoxigenic $E$. coli (ETEC) has two major virulence factors: F5 and/or F41 fimbriae that mediate adherence to the ileum and the production of heat-stable enterotoxin ( $\mathrm{STa}$ ), which is responsible for liquid hypersecretion into the gut lumen. Enteropathogenic E. coli (EPEC) causes attaching and effacing $(\mathrm{A} / \mathrm{E})$ intestinal lesions and produces intimin, an outer membrane protein encoded by the eae gene, which mediates the intimate attachment of bacteria to the enterocyte. Enterohemorrhagic E. coli (EHEC) strains cause hemorrhagic colitis (HC) or hemolytic uremic syndrome (HUS) in humans. EHEC and Shiga toxin-producing $E$. coli (STEC) produce two types of Shiga toxins: Stx1 or Stx2. Moreover, EHEC also produces intimin (eae gene) (DebRoy and Maddox 2001; Mainil 2013).

The genus Rotavirus belongs to the family Reoviridae and has a triple-layered icosahedral protein capsid. The rotavirus genome is composed of 11 double-stranded RNA (dsRNA) segments that can be differentiated by size using gel electrophoresis and can be used to identify rotavirus groups (Estes and Kapikian 2007). The virus causes a malabsorptive and toxin-mediated secretory diarrhea, mainly in calves less than 3 weeks old (Foster and Smith 2009).

The genus Coronavirus belongs to the Coronaviridae family and is divided into three distinct groups based on genetic and serologic properties. Bovine coronavirus $(\mathrm{BCoV})$ is classified as group 2 and is recognized as important cause of diarrhea in neonatal calves, winter dysentery in adult cattle, and respiratory tract infections in cattle. $\mathrm{BCoV}$ is an enveloped virus, and its genome consists of a single-stranded, positivesense RNA molecule (Clark 1993). Calves are infected with $\mathrm{BCoV}$ by oral and respiratory routes, and the virus can be detected in both the enteric and respiratory tracts (Saif et al. 1986; Heckert et al. 1990).

Few prospective longitudinal studies of enteropathogen infections in calves have been performed, and most of the studies investigated only one enteropathogen (McNulty and Logan 1983; Reynolds et al. 1985; Heckert et al. 1990; Tokhi et al. 1993; China et al. 1998; Cobbold and Desmarchelier 2000; Cummings et al. 2009a, b; Döpfer et al. 2012). Since diarrhea is a complex syndrome and involves different pathogens, severity and occurrence of disease are influenced by multiple factors that interact dynamically over time. Prevention and control of the disease are based on understanding the relationship between the multiple factors and how they interact (Blanchard 2012; Smith 2012; Cho and Yoon 2014).

Longitudinal data on enteropathogens can provide information for understanding interaction between agents, host, and environment factors and provide basis for preventive and control strategies. Therefore, it is important to perform longitudinal studies to understand the dynamics of these pathogens in young and old calves and with or without diarrhea. This prospective longitudinal study investigated the epidemiology of enteric disease associated with Salmonella spp., diarrheagenic Escherichia coli, rotavirus, and coronavirus infections in calves up to 70 days old in one dairy herd in Brazil.

\section{Materials and methods}

\section{Calves and fecal samples}

Fecal samples were collected from 67 crossbred Holstein-Gyr calves born in a dairy herd located in the city of Martinho Campos, Minas Gerais, Brazil. In 2008, the median herd size was 500 dairy Holstein cows. All calves were born in a maternity pen, separated from their dams immediately after birth and transferred to individual calf hutches. The calves were fed $2 \mathrm{~L}$ of colostrum as soon as possible after birth using buckets or bottles; thereafter, calves were bucket-fed $4 \mathrm{~L}$ of whole milk once a day in the morning and were given concentrate ad libitum for 2 months. Sand was used for bedding, and the calf hutches were surrounded by Cynodon spp. grass. No vaccine was used in the dams or in the newborns to prevent calf scours.

Fecal samples were collected directly from the rectum in plastic bags and stored at $4{ }^{\circ} \mathrm{C}$ for a maximum of 1 week until bacteriological examination and at $-20^{\circ} \mathrm{C}$ until virological examination. Samples were collected from June to August 2008, corresponding to the dry winter season. The first stool sample was collected within $24 \mathrm{~h}$ of birth, and samples were collected at weekly intervals thereafter until the animals reached 70 days of age. During an episode of diarrhea, fecal samples were collected every $24 \mathrm{~h}$ until the diarrhea ceased. Episodes of diarrhea were not treated with antibiotics. Feces were classified as diarrheic if they had a watery to paste-like consistency and the perineum and/or tail was smeared with feces; feces were classified as normal if they had a firm consistency and the perineum and tail were clean and dry.

\section{GARV and $\mathrm{BCoV}$ detection}

Fecal suspensions were prepared at a dilution of $20 \%$ in $0.05 \mathrm{M}$ Tris- $\mathrm{HCl}, 0.013 \mathrm{M} \mathrm{CaCl}_{2}$ buffer, $\mathrm{pH} 7.2$, and were centrifuged at $3000 \times g$ for $10 \mathrm{~min}$ at $4{ }^{\circ} \mathrm{C}$. The supernatants were used for RNA extraction. 
Rotavirus was detected by a modified silver-stained polyacrylamide gel electrophoresis (PAGE) procedure (Herring et al. 1982). A $500-\mu \mathrm{L}$ aliquot of the fecal suspension was treated with $100 \mu \mathrm{L}$ of lysis buffer $(10 \%$ sodium dodecyl sulfate (SDS), 100 mM EDTA pH 8.0, Sigma-Aldrich ${ }^{\circledR}$ ) and incubated in a water bath at $55{ }^{\circ} \mathrm{C}$ for $15 \mathrm{~min}$. Nucleic acids were extracted by adding $500 \mu \mathrm{L}$ of phenol-chloroformisoamyl alcohol (50:48:2) (Sigma-Aldrich ${ }^{\circledR}$ ); the mixture was homogenized, incubated in water bath at $37{ }^{\circ} \mathrm{C}$ for $10 \mathrm{~min}$, and centrifuged at $3000 \times \mathrm{g}$ for $10 \mathrm{~min}$. The aqueous phase was transferred to a new tube, and a final extraction was performed with $500 \mu \mathrm{L}$ of chloroform (Sigma-Aldrich ${ }^{\circledR}$ ) to remove traces of phenol. After homogenization, the tube was centrifuged at $3000 \times \mathrm{g}$ for $5 \mathrm{~min}$, and the aqueous phase was transferred to a new tube along with $1 \mathrm{~mL}$ of ethanol (SigmaAldrich ${ }^{\circledR}$ ) and $100 \mu \mathrm{L}$ of sodium acetate $(3 \mathrm{M})$ (Sigma-Al$\left.\operatorname{drich}^{\circledR}\right)$. The dsRNA was precipitated by keeping the tube overnight at $-20{ }^{\circ} \mathrm{C}$. The group A rotavirus NCDV strain was used as a positive control. The dsRNA was analyzed by SDS-PAGE with a $7 \%$ resolving gel and a $3.75 \%$ stacking gel and silver staining.

$\mathrm{BCoV}$ was detected using a reverse transcription reaction followed by a semi-nested PCR (SN-PCR) assay, as described by Takiuchi et al. (2006). Aliquots of $200 \mu \mathrm{L}$ of the supernatant from the fecal suspension were treated with SDS (SigmaAldrich $\left.{ }^{\mathbb{R}}\right)$ at a final concentration of $1 \%(v / v)$ and incubated at $56{ }^{\circ} \mathrm{C}$ for $30 \mathrm{~min}$. A combination of the phenol-chloroformisoamyl alcohol (Sigma-Aldrich ${ }^{\circledR}$ ) and the silica/guanidine isothiocyanate (Sigma-Aldrich ${ }^{\circledR}$ ) methods was used to extract the RNA (Alfieri et al. 2006). The RNA was eluted in $50 \mu \mathrm{L}$ of ultra-pure RNase-free DEPC-treated sterile water and used in the semi-nested PCR (SN-PCR). The BCoV cell cultureadapted Mebus strain was used as a positive control, and sterile water was used as a negative control.

\section{Bacteriological examination}

One gram of feces was diluted in $3.0 \mathrm{~mL}$ of PBS pH 7.2. From that suspension, $1.0 \mathrm{~mL}$ was inoculated into $9.0 \mathrm{~mL}$ of buffered peptone water (Difco ${ }^{\mathrm{TM}}$ ) that was incubated for $18-24 \mathrm{~h}$ at $37^{\circ} \mathrm{C}$. After incubation, one loopful of the preenrichment cultures was plated onto MacConkey agar plate and $1.0 \mathrm{~mL}$ was inoculated into $9.0 \mathrm{~mL}$ of tetrathionate broth (Difco ${ }^{\mathrm{TM}}$ ), with added 2-mL iodine-iodide solution. Both media were incubated at $37^{\circ} \mathrm{C}$ for $18-24 \mathrm{~h}$. The tetrathionate broth was then used to inoculate Hektoen and XLT4 (Difco ${ }^{\mathrm{TM}}$ ) agar plates that were incubated for $20 \mathrm{~h}$ at $37{ }^{\circ} \mathrm{C}$ (Waltman 2000). Three colonies from each agar plate, with characteristic of E. coli or Salmonella spp., were identified biochemically (Quinn et al. 1994).

The isolates identified as Salmonella spp. were serotyped at the Salmonella Reference Laboratory in the Instituto Oswaldo Cruz/Fundação Oswaldo Cruz (Rio de Janeiro, RJ, Brazil).
Identification of virulence genes from $\boldsymbol{E}$. coli

Bacterial DNA was obtained by plating the previously isolated colonies of $E$. coli into MacConkey agar, suspending the colonies in $50 \mu \mathrm{L}$ of sterile water and boiling at $100{ }^{\circ} \mathrm{C}$ for 10 min. A multiplex PCR, based on Franck et al. (1998) was performed to determine the presence of six virulence factors (Stx1, eae, F41, F5, STa, Stx2) of E. coli strains. Two E. coli reference strains were used as positive controls: B41 (ATCC 31619; O101: $\mathrm{H}^{-}: \mathrm{F}^{+} 1^{+}, \mathrm{F}^{+}, \mathrm{STa}^{+}$) and EDL 933 (ATCC 700927; O157: H7: Stx1 $1^{+}, \mathrm{Stx}_{2}^{+}$, eae $\left.^{+}\right)$. Water was used as negative control. Amplified DNA was resolved on a $2 \%$ agarose gel, stained with $0.5 \mu \mathrm{g} / \mathrm{mL}$ of ethidium bromide and photographed under UV light.

Statistical analysis

Calves were grouped according to their age as follows: $1-7,8-14,15-21,22-28,29-35,36-42,43-49,50-56$, and 57-70 days old. The chi-square test and Fisher's exact test were used at $95 \%$ significance to estimate the differences among the proportion of fecal samples that tested positive or negative for the enteropathogens studied and the age group of animals with diarrhea. The relative risk for the development of diarrhea in association with the enteropathogens was estimated with $95 \%$ confidence interval.

To calculate the frequency of diarrhea over the nine age classes, a new case was considered when animals stayed without diarrhea for five or more consecutive days. To calculate the frequency of the enteropathogens, a new case was considered when the agent was detected for the first time in each of the 9 weeks, so the frequency was not overestimated within the weeks of the study. The results were analyzed using the EpiInfo 6.0 program.

\section{Results}

In total, 850 fecal samples were collected from 67 calves from 1 to 70 days of age. Of these samples, 312 were considered diarrheic, and 538 were considered normal. Eight calves died during the experiment, but the cause of death was not identified.

The daily mean frequency of diarrheal episodes in the herd was eight cases/day, ranging from 6 to $14 \%$ of the study group. The episodes of diarrhea started between the 5 th and 13th days of age, with most cases occurring between the 9th and 11 th days. The mean duration of diarrhea was 6 days with a range of 2 to 14 days. The frequency of diarrhea was associated with specific age groups $(P<0.0001)$ (Fig. 1). The highest frequency of diarrhea was found in calves in the 
Fig. 1 Frequency of diarrhea in calves, distributed according to week of age, in one Brazilian dairy cattle herd. A total of 67 calves were sampled between June and August 2008. Columns bars followed by different letters are statistically different according to chi-square test $(P$ value $=0.05$ )

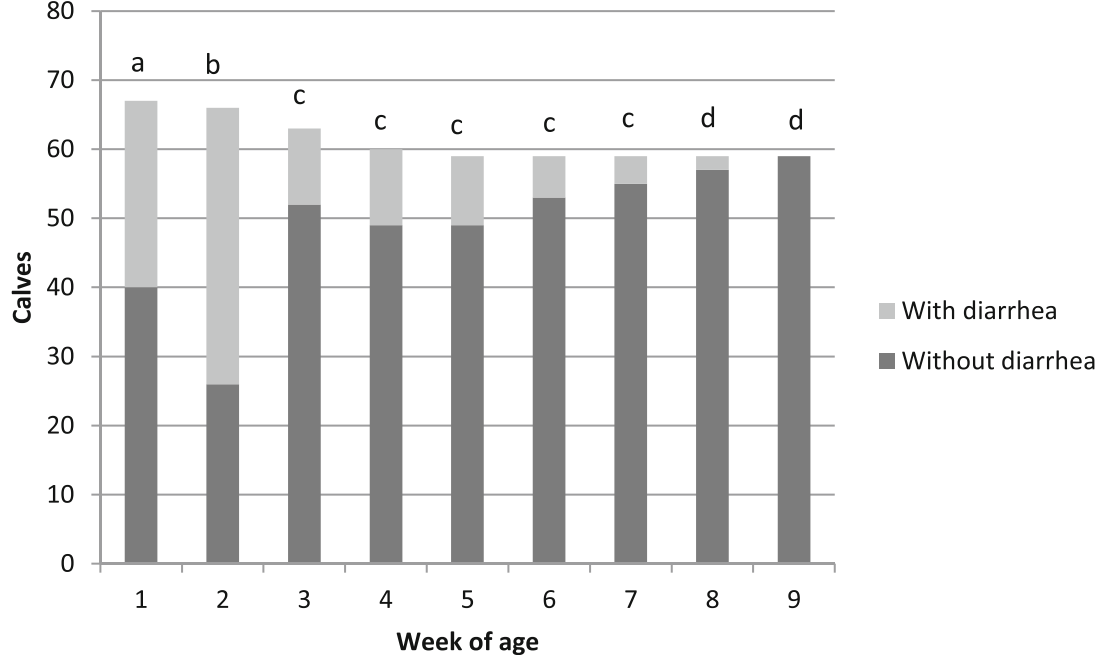

first and second age groups. After this time, cases of diarrhea progressively decreased.

Seventeen isolates of Salmonella spp. were recovered from feces of 67 calves $(11 / 67-16.4 \%)$. The serotypes identified were Salmonella agona (14/17), Salmonella enteritidis (2/17), and $S$. enterica subsp. enterica (O:4,5, flagellar structure not detectable) (1/17). The mean age of Salmonella-infected and non-diarrheic calves was 25 days, ranging from 1 to 62 days old. Only one calf, aged 7 days and infected by $S$. Agona, presented diarrhea. Statistical analysis revealed no association between the presence of Salmonella spp. and diarrhea $(P=$ $0.063)$ or age of the calves $(P=0.49)$.

E. coli were isolated from all stool samples collected. In total, 1983 E. coli strains were isolated from fecal samples and analyzed by multiplex PCR. Of the 1983 isolates, 103 were positive for at least one virulence factor: eae (7) (EPEC), K99/ STa (7) (ETEC), Stxl (7) (STEC), Stxl/eae (36) (EHEC),
Stx1/Stx2/eae (2) (EHEC), Stx2 (43) (STEC), and Stx2/eae (1) (EHEC). E. coli positive for the virulence factors studied were isolated from feces more than once in some calves. The results are summarized in Table 1. Statistical analysis revealed no association between the presence of $E$. coli pathotypes factors and diarrhea $(P=0.16)$. When comparing the week of age and the presence of $E$. coli pathotypes obtained from diarrheic animals, there was statistical association between diarrheic animals carrying E. coli Stx1/eae ${ }^{+}$in their feces with 2 and 4 weeks of age $(P=0.003)$ and $E$. coli Stx $2^{+}$with 5 weeks of age $(P=0.03)$.

Group A rotavirus (GARV) was detected in 49 (49/850 $5.7 \%)$ fecal samples collected from 33 calves (33/67$49.2 \%$ ), and only group A rotavirus electropherotype was identified by PAGE. Of those samples, 34 (34/312) fecal samples were diarrheic, and 15 (15/538) were normal (Table 2). The mean age of rotavirus infection was 18.6 days
Table 1 Virulence factors in Escherichia coli isolated from fecal samples collected from dairy calves $(n=67)$ with 0 to 67 days of age, number of calves infected with and without diarrhea, and mean age, age range, and confidence interval, measured in days. Martinho Campos, Brazil (2008)

\begin{tabular}{llllll}
\hline Virulence factors & Fecal consistency & $\begin{array}{l}\text { Number } \\
\text { of calves }\end{array}$ & Mean age & Age range & $\begin{array}{l}\text { Confidence } \\
\text { interval (95 \%) }\end{array}$ \\
\hline Intimin (eae) & Diarrhea & 2 & 31 & $26-36$ & $21.2-40.8$ \\
& Normal & 5 & 26.8 & $5-64$ & $6.3-47.3$ \\
K99/STa & Diarrhea & 4 & 14.2 & $1-30$ & $5.0-23.37$ \\
& Normal & 2 & 14.5 & $4-25$ & $0-35.1$ \\
Stx1 & Diarrhea & 4 & 14.75 & $14-17$ & $13.3-16.2$ \\
Stx1/eae & Normal & 3 & 48.33 & $41-56$ & $39.9-56.7$ \\
& Diarrhea & 11 & 17.38 & $8-34$ & $12.8-21.9$ \\
Stx1/Stx2/eae & Normal & 20 & 26.69 & $1-62$ & $19.8-33.5$ \\
& Diarrhea & 2 & 30 & $25-35$ & $20.2-39.8$ \\
Stx2 & Normal & 0 & 0 & 0 & 0 \\
& Diarrhea & 10 & 24.41 & $8-39$ & $18.7-30.1$ \\
Stx2/eae & Normal & 24 & 39.7 & $9-63$ & $35.0-44.3$ \\
& Diarrhea & 0 & 0 & 0 & 0 \\
\hline
\end{tabular}


Table 2 Bovine group A rotavirus detection by silver-stained polyacrylamide gel electrophoresis in diarrheic and non-diarrheic fecal samples collected from dairy calves in one Brazilian cattle herd, distributed according to fecal consistency, number of fecal samples, calf age (mean, minimum, and maximum), and confidence interval (95\%)

\begin{tabular}{|c|c|c|c|c|c|}
\hline \multirow{2}{*}{$\begin{array}{l}\text { Fecal } \\
\text { consistency }\end{array}$} & \multirow{2}{*}{$\begin{array}{l}\text { Number } \\
\text { of samples }\end{array}$} & \multicolumn{3}{|l|}{ Age } & \multirow{2}{*}{$\begin{array}{l}\text { Confidence } \\
\text { interval } \\
(95 \%)\end{array}$} \\
\hline & & Minimum & Maximum & Mean & \\
\hline Normal & 15 & 1 & 67 & 22.6 & $14.0-31.3$ \\
\hline Diarrhea & 34 & 1 & 38 & 16.8 & $13.8-19.8$ \\
\hline
\end{tabular}

old (95\% confidence interval (CI) 15.1-22.1). Eleven animals shed the virus more than once, with or without signs of diarrhea, and the shedding persisted for 1-3 days. An example is calf 05 , which had diarrheic feces positive for rotavirus at 15,16 , and 17 days of age and one normal stool sample positive for rotavirus at 67 days of age. Twenty-three animals positive for GARV had diarrhea, and the virus was excreted on the first $(n=16)$, second $(n=4)$, and third $(n=3)$ days of the disease episode. GARV was identified in significantly more samples of diarrheic feces $(P<0.0001)$ than in samples of feces with normal consistency, resulting in a relative risk of 2.0 (95 \% CI 1.62-2.46). There was a significant relationship between age group and diarrhea $(P=0.001)$. The frequency of rotavirus in diarrheic calves was concentrated in the first 3 weeks of age and occurred mostly in the third week (Fig. 2).

Out of 850 stool samples, $93(10.9 \%)$ were positive for $\mathrm{BCoV}$; these samples were collected from 46 calves (46/67$68.6 \%$ ) (Table 3). The mean age of infection was 25.5 days of age (95\% CI 21.3-29.1). Twenty-five calves shed the virus more than once, with or without diarrhea and intermittently. For example, calf 20 had diarrheic feces positive for $\mathrm{BCoV}$ at 34 days of age and normal stool samples at 4 and 60 days of age. Only one calf excreted the virus consecutively (for 4 days) and subsequently died. $\mathrm{BCoV}$ was detected in 22 diarrheic calves, and shedding occurred on the first $(n=16)$, second $(n=5)$, and third $(n=1)$ days of the diarrheic episode.

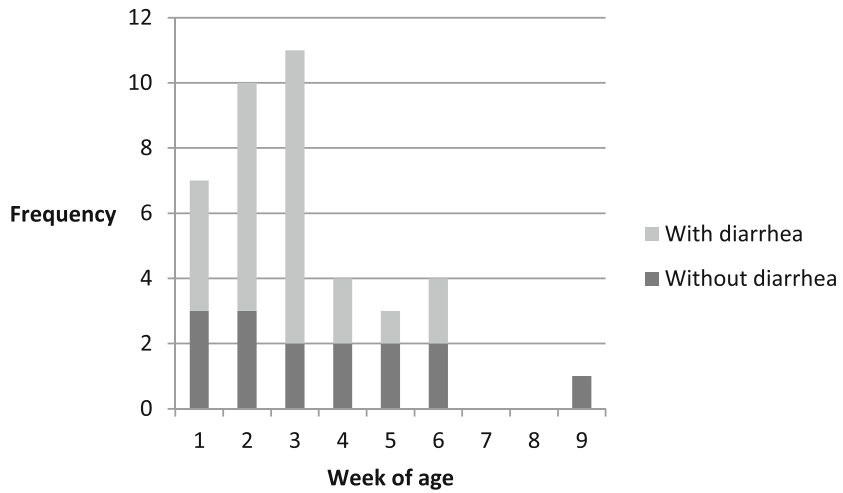

Fig. 2 Frequency of rotavirus in diarrheic and non-diarrheic dairy calves, distributed according to week of age, in one Brazilian cattle herd. A total of 67 calves were sampled between June and August 2008
Table 3 Bovine coronavirus detection by semi-nested PCR (SN-PCR) in diarrheic and non-diarrheic fecal samples collected from dairy calves in one Brazilian cattle herd, distributed according to fecal consistency, number of fecal samples, calf age (mean, minimum and maximum), and confidence interval $(95 \%)$

\begin{tabular}{|c|c|c|c|c|c|}
\hline \multirow{2}{*}{$\begin{array}{l}\text { Fecal } \\
\text { consistency }\end{array}$} & \multirow{2}{*}{$\begin{array}{l}\text { Number } \\
\text { of samples }\end{array}$} & \multicolumn{3}{|l|}{ Age } & \multirow{2}{*}{$\begin{array}{l}\text { Confidence } \\
\text { interval } \\
(95 \%)\end{array}$} \\
\hline & & Minimum & Maximum & Mean & \\
\hline Normal & 63 & 1 & 64 & 30.7 & $25.7-35.7$ \\
\hline Diarrhea & 30 & 1 & 39 & 13.8 & $10.7-16.9$ \\
\hline
\end{tabular}

Statistical analysis revealed no association between the presence of the virus and diarrhea $(P=0.346)$. However, there was an association $(P<0.0001)$ between diarrheic animals positive for $\mathrm{BCoV}$ and age group. The frequency of $\mathrm{BCoV}$ was concentrated in animals 2 and 3 weeks of age and showed a tendency to decrease after this period (Fig. 3). Considering all the pathogens investigated and each pathotype of $E$. coli as a different enteric pathogen, in total, 210 of $850(24.70 \%)$ stool samples screened were positive for at least one agent, 126 from animals without diarrhea and 84 from diarrheic ones. In 26 fecal samples, two enteropathogens were detected at the same time (Table 4).

\section{Discussion}

This longitudinal study reports the frequency of diarrhea and the presence of Salmonella, diarrheagenic E. coli, Rotavirus, and Coronavirus in diarrheic and non-diarrheic calves up to 70 days old, which were reared on a dairy farm in Brazil using management practices notably similar to those practiced in dairy cattle herds in Brazil and Latin America; therefore, the results obtained in this study can be extended to other herds.

Our study and others showed that diarrhea was highest in the second week of age (Trotz-Williams et al. 2007; Bartels et al. 2010; Smith 2012). Calf rearing in dairy cattle herds has

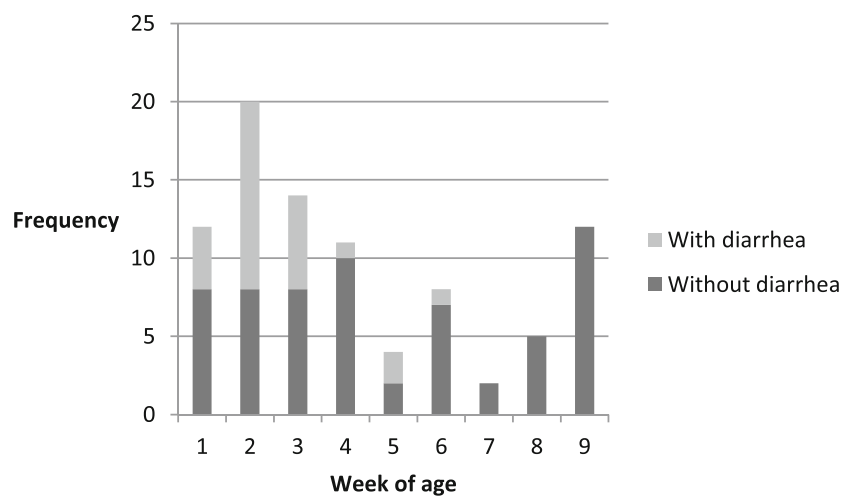

Fig. 3 Frequency of coronavirus in diarrheic calves, distributed according to week of age, in one Brazilian dairy cattle herd. A total of 67 calves were sampled between June and August 2008 
Table 4 Detection of enteropathogens and their combination in diarrheic and non-diarrheic fecal samples collected from dairy calves in one Brazilian cattle herd

\begin{tabular}{lll}
\hline Enteropathogens detected & $\begin{array}{l}\text { Number of } \\
\text { positive samples }\end{array}$ & $\begin{array}{l}\text { Number of diarrheic } \\
\text { positive samples }\end{array}$ \\
\hline Rotavirus + coronavirus & 3 & 2 \\
Rotavirus + Stx 2 & 2 & 1 \\
Rotavirus + Stx $1 /$ eae & 4 & 2 \\
Rotavirus + Stx $1 /$ Stx $2 /$ eae & 1 & 1 \\
Stx 1 /eae+ coronavirus & 6 & 2 \\
Stx $2+$ coronavirus & 7 & 3 \\
eae + coronavirus & 1 & 0 \\
K99/STa+coronavirus & 2 & 1 \\
Total & 26 & 12 \\
\hline
\end{tabular}

high costs with feeding and high mortality rates. These results demonstrate the importance of diarrhea in calves within the first 2 weeks of age and that improved management practices during this time are necessary to reduce calf scours and its consequences.

In Brazil, there is no longitudinal study for Salmonella infection in calves, and there are only few studies worldwide (Huston et al. 2002; Warnick et al. 2003; Fossler et al. 2004; Cummings et al. 2009a, b). Cummings et al. (2009a) found that $17 \%(16 / 93)$ of positive herds were responsible for over $70 \%$ of clinical cases of Salmonella which means most farms do not experience any clinical illness due to Salmonella infection and a subset of the positive properties had a very high incidence of salmonellosis. These same results were observed in this work and also by Huston et al. (2002).

Calves are infected primarily with Salmonella serotypes Dublin and Typhimurium, but different serotypes can also infect calves and clinical manifestation differences are observed between different serotypes (Barrow et al. 2010). Therefore, it is necessary to identify which serotypes are associated with disease in cattle to know the risks not only for cattle but also for human, since certain serotypes are potential zoonotic (Cummings et al. 2009a). Serotypes Agona, Enteritidis, and $S$. enterica subsp. Enterica were isolated from fecal samples in the present study and in other studies (Ambrosin et al. 2002; Younis et al. 2009; Cummings et al. 2009a, b). In our study, the low number of animals infected and the serotypes detected, added the fact that no other enteric pathogen investigated was identified in animals infected with Salmonella spp., may explain why salmonellosis was not associated with diarrhea.

There are a few reports in Brazil on the occurrence of E. coli pathotypes isolated from calves (Ambrosin et al. 2002; Langoni et al. 2004; Aidar-Ugrinovich et al. 2007; Andrade et al. 2012) and no longitudinal study. In other countries, this type of studies investigated only STEC or
STEC O157:H7 (Tokhi et al. 1993; China et al. 1998; Cobbold and Desmarchelier 2000; Döpfer et al. 2012).

Only seven out of 1983 E. coli were ETEC. This is in agreement with other surveys in Brazil that indicate a low frequency of this pathotype, which is affected by geographic, management, seasonal, and diagnostic factors (Mendonça et al. 1996; Langoni et al. 2004). ETEC was isolated from feces of diarrheic calves up to 16 days old, with the exception of one calf, which was positive for ETEC at 13 days of age and again at 30 days of age. Although ETEC affects mainly animals less than 4 days old, some studies reported the occurrence of this pathotype in older calves (de la Fuente et al. 1999; Bartels et al. 2010; Andrade et al. 2012). ETEC may occur in older calves if concurrent infection with other enteropathogens is present, and this is true for the calf 30 days old, which had feces positive for ETEC and coronavirus.

EPEC $\left(e a e^{+}\right)$, STEC $(S t x+)$, and EHEC (Stx/eae $\left.e^{+}\right)$were detected in diarrheic and non-diarrheic feces, like other reports (Blanco et al. 1997; China et al. 1998). Tokhi et al. (1993) found no association between STEC and diarrhea. All three groups EHEC, EPEC, and STEC cause diarrhea in calves (Blanchard 2012), and although there was no association with diarrhea, these pathotypes were detected as sole agents in feces of diarrheic calves and might be important enteropathogens. There was statistical association between diarrheic animals carrying E. coli Stx1/eae ${ }^{+}$(EHEC) in their feces with two and four weeks of age and E. coli Stx $2^{+}$(STEC) with five weeks of age. EHEC and STEC strains are associated with diarrhea in 1- to 8-week-old calves (DebRoy and Maddox 2001). Orden et al. (1998) found that the risk of infection with STEC increased with age. Our findings indicate STEC and EHEC, unlike ETEC, cause diarrhea mainly in calves older than 2 weeks.

We detected GARV in feces of calves with a mean age of 18.6 days. Similar results were found by Lucchelli et al. (1992) and García et al. (2000). However McNulty and Logan (1983) found a mean age of 6.1 days. However, all these studies collected feces from calves with less than 30 days old, unlike the present study, therefore, resulting in a higher mean age. These findings suggest calves are exposed to infection soon after birth and infection also occurring in older calves.

A significant difference in the frequency of rotavirus in diarrheic calves was found among those in the second and third weeks of age. Same results were found by Alfieri et al. (2006) and Mayameei et al. (2010). Bartels et al. (2010) detected the highest prevalence of GARV infection in animals within the second week of age; however, virus infection was associated with diarrhea in animals within the first week. Fecal shedding of rotavirus in diarrheic and asymptomatic calves has been reported in other studies, and as in this study, the presence of the virus in the feces was associated with diarrhea (Pérez et al. 1998; Alfieri et al. 2006; Bartels et al. 2010). 
Passive immunity may reduce the frequency of diarrhea caused by rotavirus in calves aged 1 week, and as calves get infected throughout calf rearing, the increased natural resistance reduces infection in calves older than 4 weeks (Alfieri et al. 2006). Moreover, newborn calves have slow replacement of enterocytes, and those animals are more susceptible to diarrhea. There is competition between viral replication and enterocyte replacement, and highly virulent virus could cause diarrhea in older calves (Dodet et al. 1997). These results reinforce rotavirus as an important agent of diarrhea in calves and the importance of management and prophylactic programs to reduce rotavirus infection in calves within this age group.

In experimental studies, the duration of rotavirus excretion lasted for 4-10 days (Saif et al. 1983; Hall et al. 1993). In our study, naturally infected calves, GARV was excreted for 13 days, and similar results to ours were found by Reynolds et al. (1985) that noted virus excretion lasted for 3.6 days (25 days). According to Torres-Medina et al. (1985), virus particles are present in the luminal contents $30 \mathrm{~h}$ after infection, decrease rapidly after the onset of diarrhea, and persist at lower levels over the next 5 days. These results demonstrate that in naturally infected calves, rotavirus shedding occurs for up to 3-5 days and serve as important reservoir for susceptible calves, especially young ones.

$\mathrm{BCoV}$ is widespread among Brazilian cattle herds (Stipp et al. 2009). In our study, $\mathrm{BCoV}$ was first detected in feces of calves at mean age of 13.8 days (range 1 to 64), but the mean age of the infected diarrheic animals (13.8 days) was lower than that of the non-diarrheic animals (30.7 days). Stipp et al. (2009) detected $\mathrm{BCoV}$ in calves from 1 to 60 days old, and the cases were concentrated in calves 16 to 30 days old. TorresMedina et al. (1985) showed BCoV occurs mainly in animals less than 1 month old and generally affects calves at 7 to 10 days of age. $\mathrm{BCoV}$ can infect animals up to 60 days old, and those within the second and third weeks of age develop diarrhea, due to the decrease of colostral antibodies present in the first week of age and the natural resistance acquired after infections, rendering the calf susceptible to the infection with this virus during this age (Stipp et al. 2009). It should be noticed that in our study, $\mathrm{BCoV}$ was detected in calves older than 30 days and with no diarrhea, probably because of acquired immunity, which might explain no association with diarrhea.

Positive calves shed $\mathrm{BCoV}$ in feces once or intermittently. Heckert et al. (1990) demonstrated that calves shed the virus in feces more than once. In orally inoculated animals, $\mathrm{BCoV}$ was detected in feces for one to three consecutive days and intermittently (Kapil et al. 1990; Cho et al. 2001). These findings suggest that infected calves shed the virus at various points throughout their life and can be a source of infection for young calves. Since both rotavirus and coronavirus are excreted more than once and young calves are more susceptible, it is important to consider this information when purchasing animals and managing calves of different ages.

Our study did not evaluate respiratory infections; therefore, it is not possible to assert if the $\mathrm{BCoV}$ detected in feces originated from respiratory or enteric infections. $\mathrm{BCoV}$ can infect both the respiratory and the enteric tracts, and reinfection can occur in calves. Calves inoculated with $\mathrm{BCoV}$ orally or intranasally shed the virus in the respiratory and enteric tracts and are protected from winter dysentery, diarrheic, and respiratory $\mathrm{BCoV}$ strains, demonstrating that respiratory $\mathrm{BCoV}$ plays an important role in the epidemiology and transmission of diarrhea caused by BCoV (Saif et al. 1986; Heckert et al. 1990; Cho et al. 2001).

Mixed infections with both viruses or one of the viruses and diarrheagenic $E$. coli were detected, in agreement with results of other surveys (de La Fuente et al. 1999; García et al. 2000; Ok et al. 2009). Barry et al. (2009) also detected both $\mathrm{GARV}$ and $\mathrm{BCoV}$ viruses and suggested that mixed infection could lead to a more severe outcome of the infection, resulting in a longer time to recover the intestinal villous. It is important to notice that half of the mixed infections detected in diarrheic fecal samples were collected from calves older than 4 weeks, which could be responsible for the disease.

Neonatal diarrhea has a complex etiopathogenesis, and various agents may be associated with field outbreaks; therefore, multiple infections must be considered when studying the etiology of diarrhea. Passive immunity reduces the frequency of diarrhea in calves within the first week of age, and the increased natural resistance, as calves get infected throughout calf rearing, helps to reduce diarrhea in older calves. The results of this study show that diarrhea is an important disease of young cattle with high frequency in calves in the first and second weeks of age and enteropathogens are detected in calves with diarrhea mainly within the first 3 weeks of age which could explain the high frequency of clinical signs during this age. Although Salmonella may be present in the herd, the outcome of diarrhea is affected by other factors, and Escherichia coli pathotypes should be considered when investigating the cause of diarrhea. Rotavirus and coronavirus are common viruses among diarrheic calves under 1 month of age, and calves are exposed to infection right after birth. Infected animals may shed the virus more than once, becoming a source of infection for susceptible young calves. Producers and veterinarians should focus on implementing preventive programs to reduce calf diarrhea, such as biosecurity, immunity, good nutrition, and animal welfare.

Acknowledgments This work was supported by the Conselho Nacional de Desenvolvimento Técnico e Científico-CNPq, Pró-Reitoria de Pesquisa da UFMG-PRPq, and Fundação de Amparo à Pesquisa do Estado de Minas Gerais-FAPEMIG. AAA, APL, and MBH are indebted to CNPq for the fellowships received. FMC is a fellowship recipient of the Conselho Nacional de Desenvolvimento Técnico e Científico-CNPq, Brazil. 
Ethical standards This study was conducted in agreement with the Ethical Principles in Animal Experimentation (CETEA/UFMG, protocol number 145/2006).

Conflict of interest The authors declare that they have no conflict of interest.

\section{References}

Aidar-Ugrinovich, L., Blanco, J., Blanco, M., Blanco, J,E., Leomil, L., Dahbi, G., Mora, A., Onuma, D.L, Silveira, W.D., De Castro, A.F.P., 2007. Serotypes, virulence genes, and intimin types of Shiga toxin-producing Escherichia coli (STEC) and enteropathogenic E. coli (EPEC) isolated from calves in São Paulo, Brazil, International Journal of Food Microbiology, 115, 297-30

Alfieri, A.A., Parazzi, M.E., Takiuchi, E., Médici, K.C., Alfieri, A.F., 2006. Frequency of group A rotavirus in diarrhoeic calves in Brazilian cattle herds, 1998-2002, Tropical Animal Health and Production, 38, 521-526.

Ambrosin, J.A., Almeida, F.S., Rigobelo, E.C., Castro, A.F.P., SchockenIturrino, R.P., Quintana, J.L., Avila, F.A., 2002. Epidemiological, antigenic and pathogenic profile of bovine diarrhea in a Brazilian Cattle Population, Revue d'élevage et de médecine vétérinaire des pays tropicaux, 55, 15-20.

Andrade, G.I., Coura, F.M., Santos, E.L., Ferreira, M.G., Galinari, G.C., Facury Filho, E.J., de Carvalho, A.U., Lage, A.P., Heinemann, M.B., 2012. Identification of virulence factors by multiplex PCR in Escherichia coli isolated from calves in Minas Gerais, Brazil, Tropical Animal Health and Production, 44, 1783-1790.

Barrow, P.A., Jones, M.A., Thomson, N., 2010. Salmonella. In: Gyles, C.A., Prescott, J.F., Songer, J.G., Thoen, C.O. Pathogenesis of bacterial infections in animals, (Wiley-Blackwell, Ames)

Barry, A.F., Alfieri, A.F., Stipp, D.T., Alfieri, A.A., 2009. Bovine coronavirus detection in a collection of diarrheic stool samples positive for group a bovine rotavirus, Brazilian Archives of Biology and Technology, 52, 45-49.

Bartels, C.J., Holzhauer, M., Jorritsma, R., Swart, W.A.J.M., Lam, T.J., 2010. Prevalence, prediction and risk factors of enteropathogens in normal and non-normal faeces of young Dutch dairy calves, Preventive Veterinary Medicine, 93, 162-169.

Blanchard, P.C., 2012. Diagnostics of dairy and beef cattle diarrhea, Veterinary Clinics of North America: Food Animal Practice, 28, 443-464.

Blanco, M., Blanco, J., Blanco, J.E., Mora, A., Prado, C., Alonso, M.P., Mourino, M., Madrid, C., Balsalobre, C., Juarez, A., 1997. Distribution and characterization of faecal verotoxin-producing Escherichia coli (VTEC) isolated from healthy cattle, Veterinary Microbiology, 54, 309- 319.

Brenner, F.W., Villar, R.G., Angulo, F.J., Tauxe, R., Swaminathan, B., 2000. Salmonella nomenclature, Journal of Clinical Microbiology, $38,2465-2467$.

China, B., Pirson, V., Mainil, J., 1998. Prevalence and molecular typing of attaching and effacing Escherichia coli among calf populations in Belgium, Veterinary Microbiology, 63, 249-259.

Cho, Y.I. and Yoon, K.J., 2014. An overview of calf diarrhea - infectious etiology, diagnosis and intervention, Journal of Veterinary Science, $15,1-17$.

Cho, K.O., Hasoksuz, M., Nielsen, P.R., Chang, K.O., Lathrop, S., Saif, L.J., 2001. Cross-protection studies between respiratory and calf diarrhea and winter dysentery coronavirus strains in calves and RT-PCR and nested PCR for their detection, Archives of Virology, 146, 2401-2419.
Clark, M.A., 1993. Bovine Coronavirus, British Veterinary Journal, 149, $51-70$.

Cobbold, R., Desmarchelier, P., 2000. A longitudinal study of Shigatoxigenic Escherichia coli (STEC) prevalence in three Australian dairy herds, Veterinary Microbiology, 71, 125-137.

Cummings, K.J., Warnick, L.D., Alexander, K.A., Cripps, C.J., Grohn, Y.T., James, K.L., Mcdonough, P.L., Reed, K.E., 2009a. The duration of fecal Salmonella shedding following clinical disease among dairy cattle in northeastern USA, Preventive Veterinary Medicine, 92, 134-139.

Cummings, K.J., Warnick, L.D., Alexander, K.A., Cripps, C.J., Gröhn, Y.T., Mcdonough, P.L., Nydam, D.V., Reed, K.E., 2009b. The incidence of salmonellosis among dairy herds in the northeastern United States, Journal of Dairy Science, 92, 3766-3774.

De La Fuente, R., Luzón, M., Ruiz-Santa-Quiteria, J.A., García, A., Cid, D., Orden, J.A., García, S., Sanz, R., Gómez-Bautista, M., 1999. Cryptosporidium and concurrent infections with other major enterophatogens in 1 to 30-day-old diarrheic dairy calves in central Spain, Veterinary Parasitology, 80, 179-185.

DebRoy, C., Maddox, C.W., 2001. Identification of virulence attributes of gastrointestinal Escherichia coli isolates of veterinary significance, Animal Health Research Reviews, 2, 129-140.

Dodet, B., Heseltine, E., Mary, C., Salion, P., 1997. Rotaviruses in human and veterinary medicine. Trends in Microbiology, 5, 176-178.

Döpfer, D., Geue, L., Schares, S., Mintel, B., Hoffmann, B., Fischer, E.A., 2012. Dynamics of shiga-toxin producing Escherichia coli (STEC) and their virulence factors in cattle, Preventive Veterinary Medicine, 103, 22-30.

Estes, M., Kapikian, A.Z., 2007. Rotaviruses. In: Knipe, D.M., Howley, P.M. Fields Virology, (Lippincott Williams \& Wilkins, Philadelphia)

Fossler, C.P., Wells, S.J., Kaneene, J.B., Ruegg, P.L., Warnick, L.D., Bender, J.B., Godden, S.M., Halbert, L.W., Campbell, A.M., Geiger-Zwald, A,M., 2004. Prevalence of Salmonella spp on conventional and organic dairy farms, Journal of the American Veterinary Medical Association, 225, 567-573

Foster, D.M., Smith, G.W., 2009. Pathophysiology of diarrhea in calves, Veterinary Clinics of North America: Food Animal Practice, 25, 13-36.

Franck, S.M., Bosworth, B.T., Moon, H.W., 1998. Multiplex PCR for enterotoxigenic, attaching and effacing, and Shiga toxin-producing Escherichia coli strains from calves, Journal of Clinical Microbiology, 36, 1795-1797.

García, A., Ruiz-Santa-Quiteria, J.A., Orden, J.A., Cid, D., Sanz, R., Gómez-Bautista, M., De La Fuente, R., 2000. Rotavirus and concurrent infections with other enteropathogens in neonatal diarrheic dairy calves in Spain, Comparative Immunology, Microbiology and Infectious Diseases, 23, 175-183.

Hall, G.A., Bridger, J.C., Parsons, K.R., Cook, R., 1993. Variation in rotavirus virulence: a comparison of pathogenesis in calves between two rotaviruses of different virulence, Veterinary Pathology, 30, 223-233.

Heckert, R.A., Saif, L.J., Hoblet, K.H., Agnes, A.G., 1990. A longitudinal study of bovine coronavirus enteric and respiratory infections in dairy calves in two herds in Ohio, Veterinary Microbiology, 22, 187-201.

Herring, A.J., Inglis, N.F., Ojeh, C.K., Snodgrass, D.R., Menzies, J.D., 1982. Rapid diagnosis of rotavirus infection by direct detection of viral nucleic-acid in silver stained polyacrylamide gels, Journal of Clinical Microbiology, 16, 473-477.

Huston, C.L., Wittum, T.E., Love, B.C., 2002. Persistent fecal Salmonella shedding in five dairy herds, Journal of the American Veterinary Medical Association, 220, 650-655.

Kapil, S., Trent, A.M., Goyal, S.M., 1990. Excretion and persistence of bovine coronavirus in neonatal calves, Archives of Virology, 115, $127-13$.

Langoni, H., Linhares, A.C., Avila, F.A., da Silva, A.V., Elias, A.O., 2004. Contribution to the study of diarrhea etiology in neonate dairy 
calves in São Paulo State, Brazil, Brazilian Journal of Veterinary Research and Animal Science, 41, 313-319.

Lucchelli, A., Lance, S.E., Bartlett, P.B., Miller, G.Y., Saif, L.J., 1992. Prevalence of bovine group A bovine rotavirus shedding among dairy calves in Ohio, American Journal of Veterinary Research, 53, $169-179$.

Mainil, J, 2013. Escherichia coli virulence factors, Veterinary Immunology and Immunopathology, 152, 2-12.

Mayameei, A., Mohammadi, G., Yavari, S., Afshar, E., Omidi, A., 2010. Evaluation of relationship between Rotavirus and Coronavirus infections with calf diarrhea by capture ELISA, Comparative Clinical Pathology, 19, 553-557.

McNulty, M.S., Logan, E.F., 1983. Longitudinal survey of rotavirus infection in calves, Veterinary Record, 113, 333-335.

Mendonça, C.L., Lazaro, N.S., Castro, R.S., Afonso, J.A.B.., Hofer, E., 1996. Occurrence of enterotoxigenic Escherichia coli and Salmonella sp. in calves in southern Agreste region of the State of Pernambuco, Brazil, Pesquisa Veterinária Brasileira, 16, 127-131.

Ok, M., Güler, L., Turgut, K., Ok, Ü., Sen, I., Günduz, I.K., Birdane, M.F., Güzelbektes, H., 2009. The studies on the aetiology of diarrhoea in neonatal calves and determination of virulence gene markers of Escherichia coli strains by multiplex PCR, Zoonoses and Public Health, 56, 94-101.

Orden, J.A., Ruiz-Santa-Quiteria, J.A., Cid, D., Garcia, S., Sans, R., De La Fuente, R., 1998. Verotoxin-producing Escherichia coli (VTEC) and eae-positive non-VTEC in 1-30 days-old diarrhoeic dairy calves, Veterinary Microbiology, 63, 239-248.

Pérez, E., Kummeling, A., Janssen, M.M.H., Jiménez, C., Alvarado, R., Caballero, M., Donado, P., Dwinger, R.H., 1998. Infectious agents associated with diarrhoea of calves in the canton of Tilaran, Costa Rica, Preventive Veterinary Medicine, 33, 195-205.

Quinn, P.J., Carter, M.E., Markey, B., Carter, G.R., 1994. Enterobacteriaceae. In: Quinn, P.J., Carter, M.E., Markey, B., Carter, G.R. Clinical Veterinary Microbiology. (Wolfe, London)

Reynolds, D., Hall, G., Debney, T., Parsons, K., 1985. Pathology of natural rotavirus infection in clinically normal calves, Research in Veterinary Science, 38, 264-269.

Saif, L.J., Redman, D.R., Smith, K.L., Theil, K.W., 1983. Passive immunity to bovine rotavirus in newborn calves fed colostrum supplements from immunized or nonimmunized cows, Infection and Immunity, 41, 1118-1131.

Saif, L.J., Redman, D.R., Theil, K.W., 1986. Experimental coronavirus infection in calves: viral replication in the respiratory and intestinal tracts, American Journal of Veterinary Research, 47, 1426-1432.

Smith, D.R., 2012. Field disease diagnostic investigation of neonatal calf diarrhea, Veterinary Clinics of North America: Food Animal Practice, 28, 465-481.

Stipp, D.T., Barry, A.F., Alfieri, A.F., Takiuchi, E., Amude, A.M., Alfieri, A.A., 2009. Frequency of BCoV detection by a semi-nested PCR assay in faeces of calves from Brazilian cattle herds, Tropical Animal Health and Production, 41, 1563-1567.

Takiuchi, E., Stipp, D.T., Alfieri, A.F., Alfieri, A.A., 2006. Improved detection of bovine coronavirus $\mathrm{N}$ gene in faeces of calves infected naturally by a semi-nested PCR assay and an internal control, Journal of Virological Methods, 131, 148-154

Tokhi, M., Peiris, J.S.M., Scotland, S.M., Willshaw, G.A., Smith, H.R., Cheasty, T., 1993. A longitudinal study of vero cytotoxin producing Escherichia coli in cattle calves in Sri Lanka, Epidemiology and Infection, 110, 197-208.

Torres-Medina, A., Schlafer, D.H., Mebus, C.A., 1985. Rotaviral and coronaviral diarrhea, Veterinary Clinics of North America: Food Animal Practice, 1, 471-493.

Trotz-Williams, L.A., Martin, S.W., Leslie, K.E., Duffield, T., Nydam, D.V., 2007. Peregrine AS. Calf-level risk factors for neonatal diarrhea and shedding of Cryptosporidium parvum in Ontario dairy calves, Preventive Veterinary Medicine, 82, 12-28.

Waltman, W.D., 2000. Methods for the cultural isolation of Salmonella. In: Wray, C., Wray, A. Salmonella in Domestic Animals, (CABI Publishing, London)

Warnick, L.D., Kanistanon, K., McDonough, P.L., Power, L., 2003. Effect of previous antimicrobial treatment on fecal shedding of Salmonella enterica subsp. Enterica serogroup b in New York dairy herds with recent clinical salmonellosis, Preventive Veterinary Medicine, 56, 285-297.

Younis, E.E., Ahmed, A.M., El-Khodery, S.A., Osman, S.A., El-Naker, Y.F.I., 2009. Molecular screening and risk factors of enterotoxigenic Escherichia coli and Salmonella spp. in diarrheic neonatal calves in Egypt, Research in Veterinary Science, 87, 373-379. 